\title{
Zararına Sevinme (Schadenfreude) ve Yardım Davranışlarının Karanlık Üçlü; Benlik Saygısı, Empati ve Bakış Açısı Alma Bakımından İncelenmesi
}

\author{
Dr. Öğr. Üyesi Seda ERZİ* \\ Maltepe Üniversitesi, İnsan ve Toplum Bilimleri Fakültesi, Psikoloji Bölümü, İstanbul/ Türkiye, \\ sedaerzi@maltepe.edu.tr, ORCID: 0000-0003-4450-158X
}

\section{$\ddot{\mathbf{O} z}$}

Bu çalışmanın amacı, zararına sevinme (schadenfreude) ve yardım davranışının, karanlık üçlü, benlik saygısı, empati ve bakış açısı alma bakımından incelenmesidir. Çalışmaya 245 kadın, 49 erkek üniversite öğrencisi katılmıştır $(M=21.25$, ss=3.47). Katılımcılar sırasıyla, karanlık üçlü, benlik saygısı, kişilerarası tepkisellik indeksi (empati ve bakış açısı alma alt ölçekleri) sorularını cevaplamışlardır. Bunun ardından katılımcılara 3 farklı türde senaryo verilmiştir. Katılımcılar, her senaryo için zararına sevinme ve sempati duygusunu ölçmek amacıyla hazırlanan soruları, ardından da yardım davranışı ile ilgili soruları cevaplamışlardır. Bulgulara göre, yardım davranışı, zararına sevinme, benlik saygısı, Makyavelizm, psikopati, bakış açısı alma ve empati değişkenleri bakımından anlamlı düzeyde açıklanmıştır. Zararına sevinme ise, sempati, Makyavelizm, narsisizm, psikopati, bakış açısı alma, empati, benlik saygısı ve yardım davranışı bakımından anlamlı düzeyde açıklanmıştır. Yüksek düzeyde psikopati ve Makyavelizm yüksek düzeyde zararına sevinme ile ilişkilidir. Yüksek düzeyde yardım davranışı düşük düzeyde zararına sevinme ile ilişkilidir. Bulgular ilgili alanyazın 1şı̆̆ında tartışılmıştır.

Anahtar Kelimeler: Zararına sevinme; Yardım davranışı; Karanlık üçlü; Benlik saygis1; Empati. 


\title{
Examining Schadenfreude and Helping Behavior in \\ Terms of Dark Triad, Self Esteem, Perspective Taking \\ and Empathy
}

\begin{abstract}
The aim of this study was to examine the schadenfreude and helping behavior in terms of taking a dark triad, self-esteem, empathy and perspective taking. 245 female and 49 male university students participated in the study $(\mathrm{M}=21.25, \mathrm{sd}=3.47)$. Participants answered the questions of Dark Triad, the self-esteem, Interpersonal reactivity Index (empathy and perspective-taking subscales), respectively. Then the participants were given 3 different types of scenarios. Participants answered the questions of schadenfreude and sympathy for each scenario. Then they answered the question about helping behavior. According to the results, helping behavior was predicted significantly by schadenfreude, self-esteem, Machiavellianism, psychopathy, perspective taking and empathy. Schadenfreude was predicted significantly by sympathy, Machiavellianism, narcissism, psychopathy, perspective taking, empathy, self-esteem and helping behavior. High levels of psychopathy, and a high level of Machiavellianism are associated with high levels of schadenfreude. High levels of helping behaviors are associated with low levels of schadenfreude. Results of the study are discussed within the light of literature.
\end{abstract}

Keywords: Schadenfreude; Helping behavior; Dark triad; Self-Esteem; Empathy.

\section{Extended Summary}

\section{Purpose}

Someone's pain causes sympathy for those who are exposed to this situation (Eisenberg, Fabes and Spinrad, 2006). However, at times the pain or sorrow of someone else may cause the individual who has witnessed it to enjoy this situation. In the literature, this is indicated by the German word schadenfreude (Feather, Wenzel and McKee, 2013). As previously mentioned, someone else's sadness can often lead to sympathy for him and subsequent helping behavior. However, the studies on how schadenfreude affects the helping behavior are very limited. In a study by Schulz, Rudolph, Tscharaktschiew and Rudolph (2013), it was found that schadenfreude was negatively correlated with helping behaviors. On the contrary, schadenfreude was positively associated with Machiavellianism, psychopathy and narcissistic traits 
and antisocial behaviors underlined as the dark side of personality (James et al., 2014). The number of studies in which helping behaviors and dark triad personality traits are investigated together is quite limited. On the other hand, a negative relationship was found between empathy level and Machiavellianism (Barnett and Thompson, 1985). In this study, it is aimed to examine the relationship between the sense of schadenfreude and helping behavior of people by using different scenarios in terms of dark triad, self-esteem, empathy and perspective taking.

\section{Method}

245 female and 49 male university students participated in the study $(\mathrm{M}=21.25, \mathrm{ss}=3.47)$. Participants answered the questions of Dark Triad, selfesteem, Interpersonal reactivity Index (empathy and perspective-taking subscales), respectively. Then the participants were given 3 different types of scenarios. Participants answered the questions of schadenfreude and sympathy for each scenario. Then they answered the question about helping behavior.

\section{Results}

According to first hypothesis of the study, linear regression analysis was performed to determine the predictors of helping behavior. Self-esteem, second schadenfreude and sympathy scenario, Machiavellianism, psychopathy, empathy and perspective taking was found to explain $14 \%$ of the helping behavior variance. Only psychopathy and empathy score were contributed significantly to the model $(p<.05)$. According to second hypothesis, linear regression analysis was performed to determine the predictors of the 3 different schadenfreude scenarios. It was observed that the first schadenfreude scenario was explained by sympathy and Machiavellianism scores $(p<.001)$. The second schadenfreude scenario was explained by sympathy, Machiavellianism, narcissism, psychopathy, perspective taking, empathy, self-esteem, and helping behavior. The variables that contributed significantly to the model were Machiavellianism, psychopathy and sympathy $(p<.01)$. It was found that the third schadenfreude scenario was explained by sympathy, Machiavellianism psychopathy and perspective taking. Machiavellianism and sympathy significantly contributed to the model $(p<.001)$.

\section{Discussion}

The results of the study showed that helping behaviors were explained by self-esteem, situational schadenfreude, and sympathy, Machiavellianism, psychopathy, empathy and perspective taking. However, only variables that 
contributed significantly to the model were empathy and psychopathy. In this context, it is thought that in the future studies, behavioral measures will be more contributing to understanding the relationship between schadenfreude and helping behavior. For schadenfreude only the second scenario was associated with dark triad traits, self-esteem, empathy, perspective taking and helping behaviors. Other schadenfreude scenarios were explained significantly by sympathy and Machiavellianism. The second scenario included competition and personal gain so it is thought that dark triad personality traits such as psychopathy could play an important role in that scenario.

\section{Conclusion}

In summary, results of the study showed that schadenfreude, experience of pleasure at another's misfortune was indirectly related to helping behaviors, psychopathy and Machiavellianism. Limitations are demographic characteristics of the participants and the absence of behavioral measures. It is thought that future studies should be conducted participants with different demographic characteristics and it will contribute to the relevant literature.

\section{Giriș}

Başkasının üzüntüsü ya da acısı, bu duruma maruz kalanların sıklıkla ona karşı sempati (acıma) duymasına ve ona yardım etme girişiminde bulunmasina neden olmaktadır (Eisenberg, Fabes ve Spinrad, 2006). Ancak bazı zamanlarda başka birinin acısı ya da üzüntüsü, buna tanıklık eden bireyin bu durumdan hoşlanmasına, keyiflenmesine hatta zevk almasına yol açabilmektedir. Alanyazında bu durum Almanca bir kelime olan "schadenfreude" kavramılla belirtilmektedir (Feather, Wenzel ve McKee, 2013). Başkasının üzüntüsünden zevk almak, filozoflar tarafından kullanılan bir kavram olmuştur. Örneğin Aristoteles, Nikomakhos'a Etik kitabında (1108b/1-10), kıskançlık ve hasetin ortasında duran bir duygu olarak infialden bahsetmiş; infiali, haksız yere iyi durumda olanlar karşısında acı duyma, kıskançlığı, iyi durumda olan herkes karşısında acı duyma, haseti ise başkasının acı duymasına sevinme olarak tanımlamıştır. Schopenhauer (1841/2014) zararına sevinme duygusunu, "başkalarının başına gelecek talihsizliklerden duyulan haince bir zevk" olarak tanımlamıştır (s.22). Zararına sevinme duygusu genellikle olumsuz bir çağrışım yaptığı hâlde, bu duygunun deneyimlenmesi çok nadir değildir. Ülkemizde bu konuyla ilgili yapılan çalışmalar oldukça azdır. Yeniay (2012) tarafından yapılan çalışmada, duygusunun sosyal kimlik bağlamında dış gruba 
mensup kişinin başına gelen talihsiz duruma karşı sevindikleri ve zararına sevinme duygusu deneyimledikleri görülmüştür. Aynı zamanda başına talihsiz durum gelen kişinin bunu hak etme düzeyi de bu olaya sevinme düzeyini etkilemiştir. Tatlıcıoğlu (2015) tarafından yapılan çalışmada, dolaylı utanma ve zararına sevinme arasındaki ilişki incelenmiştir. Dolaylı utanma eğilimi arttıkça başkalarının zararına sevinme duygusunun da azaldığı tespit edilmiştir. Torun (2013) tarafından yapılan çalışmada, kıskançlık ve zararına sevinme arasındaki ilişkiye bakılmıştır. Buna göre, farklı sosyo-demografik yapıdaki bireylerin, kendilerinden daha iyi durumda olanlara karşı kıskançlık hissedebildiği bununla birlikte, kıskançlık hissettikleri kişilerin başlarına gelen talihsiz durumlarda zararına sevinme hissettikleri görülmüştür. Smith, Powell, Combs ve Schurtz (2009) bu duygunun, bireysel kazanımlar, iç grup dış grup dinamikleri, sosyal kıyaslama, haset gibi unsurlarla ilişkili olduğunu belirtmiştir. Bu bağlamda zararına sevinme, insanın sosyal ve duygusal bir varlık olmasıyla ilişkilidir. Buradan hareketle, bu çalışmada zararına sevinme duygusunun yardım davranışlarıyla ilişkisinin çeşitli değişkenlerle birlikte araştırilması hedeflenmiştir.

Daha önce belirtildiği gibi başkasının üzüntüsü, genellikle ona karşı sempati duygusuna ve akabinde yardım davranışının gerçekleşmesine neden olabilmektedir. Ancak başkasının üzüntüsünden zevk alma olarak ifade edilen zararına sevinme duygusunun, yardım davranışına nasıl etki edebileceğine ilişkin yapılan çalışmalar oldukça sınırlıdır. Schulz, Rudolph, Tscharaktschiew ve Rudolph (2013) tarafından yapılan çalışmada, zararına sevinme duygusunun yardım davranışlarıyla negatif yönde, sempati duygusunun pozitif (olumlu) yönde ilişkili olduğu bulunmuştur. Benzeri biçimde, olumlu sosyal medya kullanımının özellikle bu davranışları teşvik eden oyunlar oynamanın empati duygusunu arttırırken, zararına sevinme duygusunu azalttığı bulunmuştur (Greitemeyer, Osswald ve Brauer, 2010).

Yardım davranışının aksine, zararına sevinme duygusunun, kişiliğin karanlık tarafları olarak altı çizilen, Makyavelizm, psikopati ve narsisistik özellikler ve antisosyal davranışlarla ile pozitif yönde ilişkili olduğu belirtilmiştir (James, Kavanagh, Jonason, Chonody ve Scrutton, 2014). Karanlık üçlü kavramı, Makyavelizm, narsisizm ve psikopati özelliklerini birlikte ele almaktadır; söz konusu kavram ilk kez Paulhus ve Williams (2002) tarafından kullanılmıştır. Bu üç kişilik özelliğinin ortak tarafları, bencillik, insan ilişkilerinin çıkar odaklı olması, çıkarlar doğrultusunda çevresindekileri yönlendirme, 
uyumsuzluk olarak belirtilmektedir. Narsisizm, kişinin kendi sahip olduğu nitelikleri abartması, başkaları üzerinde otorite kurma eğilimi, güç elde etme istenci, bencillik gibi özelliklerle karakterize edilmektedir. Makyavelizm, kişisel çıkarların maksimize edilmesi (üst seviyeye çıkarılması), insanları yönlendirme ve yönetme istenci, yönlendirmeye başvurmak gibi özellikler tanımlanmaktadır. Psikopati ise, ahlak dışı davranma eğilimi, vicdan azabı duymama, sorumluluk hissetmeme, dürtüsel davranma, saldırgan ve anti-sosyal davranma gibi özelliklerle karakterize edilmiştir (Özsoy ve Ardıç, 2017).

Zararına sevinme duygusunun, karanlık üçlü olarak belirtilen bu kişilik özellikleriyle ilişkili olabileceği düşünülmektedir. Nitekim Porter, Bhanwer, Woodworth ve Black (2014) karanlık kişilik özelliklerine (makyevelizm, narsisizm) sahip bireylerin, daha fazla zararına sevinme duygusu ifade ettiklerini ve zor duruma düşen bireylere karş1 daha yoğun biçimde gülme davranış1 gösterdikleri bulmuştur. Karanlık üçlü kişilik özellikleri daha çok antisosyal davranışlarla ilişkisi araştırılmıştır (Kerig ve Stellwagen, 2010; Porter ve ark., 2014). Yardım davranışları ile karanlık üçlü kişilik özelliklerinin birlikte araştırıldığı çalışma sayısı oldukça sınırlıdır. Buna karşın, empati düzeyi ve makyevelizm arasında negatif yönde ilişki bulunmuş; Makyavelizm düzeyi fazla olan çocukların daha az yardım davranışında bulundukları gözlenmiştir (Barnett ve Thompson, 1985). Bu çalışmada, zararına sevinme duygusu ve yardım davranışlarının karanlık üçlü kişilik özellikleri ile ilişkisinin araştırılması hedeflenmiştir.

Zararına sevinme duygusu, yapılan çalışmalarda, benlik saygısı ile ilişkili bulunmuştur (Brambilla ve Riva, 2017; Jung, 2017; Van Dijk ve Ouwerkerk, 2014; Van Dijk, Ouwerkerk, Wesseling ve Van Koningsbruggen, 2011). Aşağ 1 doğru kıyaslama kuramına göre, herhangi bir durumdan olumsuz etkilenen kişiler, daha az şanslı bir diğeriyle karşılaştırıldığında, bu durum öznel iyi oluş düzeyini arttırıcı bir etkiye sahiptir, diğer bir deyişle bireylerin kendilerinden memnun olma seviyelerinin artması, değer verdikleri unsurlar bak1mından diğerlerinden üstün olduklarını düşünmeleri yoluyla gerçekleşmektedir (Wills, 1981). Örneğin, Van Dijk, Ouwerkerk, Nieweg, Van Koningsbruggen ve Wesseling (2009) tarafından yapılan çalışmada, başkalarının başına gelen talihsiz olaylar neticesinde, kişilerin benlik saygılarının arttığı bulunmuştur. Benzeri biçimde Jung (2017) tarafindan yapılan çalışmada, kişilerin benlik saygısı yüksek olduğunda, daha az zararına sevinme duygusu gösterdikleri bulunmuştur. Benlik saygısının aynı zamanda yardım davranışlarıyla 
ilişkili olduğu tespit edilmiştir (Jacobs, Vernonve Eccles, 2004; Laible, Carlo ve Roesch, 2004, Luengo-Kanacri, Pastorelli, Eisenberg, Zuffianò ve Caprara, 2013; Zuffianò, Eisenberg, Alessandri, Luengo-Kanacri, Pastorelli, Milioni ve Caprara, 2014). Bu bağlamda bu çalışmada zararına sevinme duygusu ve yardım davranışlarının benlik saygısı ile ilişkisinin araştırılması hedeflenmiştir.

Daha önce belirtildiği gibi sempati duygusu yardım davranışlarıyla ilişkilendirilmiştir (Eisenberg, Fabes ve Spinrad, 2006). Bunun yanı sıra, yardım davranışlarının empati duygusu ile ilişkili olduğu bilinmektedir. Hoffman (2000) ben ve öteki ayrımın oluşmasıyla birlikte, 24 aylıktan itibaren bebeklerin diğerinin içinde bulunduğu sıkıntıyı anlayabilme becerisini göstermeye başlarlar. Tam olarak ötekinin içsel durumunu kavrayamasalar bile onun s1kıntısını gidermek adına yardım davranışlarında bulunabilirler. Çocuklar zihin kuramı becerileri bakımından geliştiklerinde ise, empati kurabilme becerileri artış göstermektedir. Yardım davranışları aynı zamanda bakış açısı alma özellikleri ile de ilişkilidir. Batson ve Powell (2003), bakış açısı alma becerisinin gelişiminin, yardıma ihtiyacı olan ötekiyle özdeşim kurabilmesine, onu anlama ve sempati duygusu hissetmesine katkı sağlayacağını belirtmiştir. $\mathrm{Bu}$ bağlamda empati ve bakış açısı alma becerilerinin gelişimi, diğerini anlama ve ona yardım davranışında bulunmayla ilişkilendirilmiştir (Eisenberg, Zou ve Koller, 2001; Kumru, Carlo, Mestre ve Samper, 2012). Yapılan çalışmalarda zararına sevinme duygusunun ağırlıklı olarak sempati duygusu ile negatif yönde ilişki olduğu bulunmuştur (Schulz ve ark., 2013). Bu çalışmada bu nedenle sempati duygusu da ölçülmüştür. Bunun yanı sıra, Greenier (2018) tarafından yapılan çalışmada zararına sevinme empati ile negatif yönde ilişkili bulunmuştur. Benzeri biçimde, Greitemeyer ve arkadaşları (2010) zararına sevinme duygusunun empati duygusunu azalttığını bulmuşlardır. Zararına sevinme duygusunun deneyimlenmesi bakış açısı alma özellikleri ile ilişkilidir (Shamay-Tsoory, Tibi-Elhanany ve Aharon-Peretz, 2007). Bakış açısı alma becerilerinin aynı zamanda empati duygusunu harekete geçirebilmede önemli olduğu vurgulanmaktadır (Van Lange, 2008). Buradan hareketle bu çalışmada yardım davranışı ve zararına sevinme duygusu arasındaki ilişkide, empati ve bakış açısı alma özelliklerinin de araştırılması hedeflenmiştir.

Zararına sevinme ile ilgili yapılan çalışmalarda ağırlıklı olarak senaryolar kullanılmaktadir (Feather, Wenzel ve McKee, 2013; Jung, 2017; Van Dijk ve ark., 2014). Bu çalışmada aynı yöntem kullanılarak 3 farklı senaryo oluşturulmuştur. Smith, Powell, Combs ve Schurtz (2009) zararına sevinme 
duygusunun ortaya çıkabilmesini sağlayan temel unsurları: kişisel kazanım (rekabet), hak ettiğini bulma ve sosyal kıyaslama olarak belirtmiştir. Bu bağlamda oluşturulan 3 farklı senaryonun, zararına sevinme duygusunun kapsamını içeren bu 3 farklı unsura dayandırılması amaçlanmıştır. Kullanılan ilk senaryo hak ettiğini bulma, ikinci senaryo kişisel kazanım, üçüncü senaryo ise sosyal kıyaslama duygusu kapsamında geliştirilmiştir.

Buradan hareketle bu çalışmada, farklı senaryolar kullanılarak, zararına sevinme duygusu ve yardım davranışı arasındaki ilişkinin, karanlık üçlü, benlik saygısı, empati, bakış açısı alma özellikleri bakımından incelenmesi hedeflenmiştir. Çalışmanın birinci hipotezi, yardım davranışının, zararına sevinme, karanlık üçlü kişilik özellikleri, benlik saygısı, empati ve bakış açısı alma özellikleri bakımından anlamlı düzeyde yordanmasıdır. Çalışmanın ikinci hipotezi zararına sevinme duygusunun, karanlık üçlü kişilik özellikleri, benlik saygısı, sempati, bakımından anlamlı düzeyde yordanmasıdır.

\section{Yöntem}

\section{Katılımcılar}

Çalışmaya Maltepe Üniversitesinde okuyan 245 kadın, 49 erkek öğrenci katılmıştır. Katılımcıların yaş ortalaması 21.25 'tir (ss=3.47). Katılımc1ların annelerinin \%2.4'ü okuryazar değil, \%27.2'si ilkokul, \%17.3'ü ortaokul, \%28.9'u lise mezunu, \%22.1'i lisans, \%2'si yüksek lisans mezunudur. Kat1lımcıların babalarının \%0.7'si okuryazar değil, \%16'sı ilkokul, \%14.6'sı ortaokul, \%37.1'i lise mezunu, \%26.9'u lisans, \%4.8'i yüksek lisans mezunudur.

\section{Veri Toplama Araçları}

Bu bölümde çalışmada kullanılan veri toplama araçları hakkında bilgi verilmiştir. Bu araçlar; Karanlık Üçlü Ölçeği, Rosenberg Benlik Saygısı Ölçeği, Kişilerarası Tepkisellik İndeksi (empati ve bakış açısı alma alt ölçekleri), araştırmacı tarafından oluşturulan senaryolar ve yardım davranışı ölçümlerini içermektedir.

Demografik Bilgi Formu: Katılımcılardan, cinsiyet, yaş, eğitim durumu, anne ve baba eğitimi ile ilgili demografik bilgi alınmıştır.

Karanlı Üçlü Ölçeği: 27 maddeden oluşan bu ölçek Jones ve Paulhus (2014) tarafından geliştirilmiştir. Makyavelizm, narsisizm ve subklinik psikopati kişilik özelliklerini ölçen 3 alt boyutu vardır ve 5'li likert tipidir. Jones ve Paulhus (2014) tarafından yapılan güvenirlik çalışmasında Cronbach Alfa değerleri, Makyavelizm için .80 , narsisizm için .72 ve subklinik psikopati için .79 
olarak bulunmuştur. Ölçeğin Türk kültürüne adaptasyonu Özsoy, Rauthmann, Jonason ve Ardıç (2017) tarafindan yapılmış, Cronbach Alfa değerleri sırasıyla $.70, .79$ ve .79 olarak bulunmuştur. Bu çalışmada Cronbach Alfa güvenirlik katsayısı Makyavelizm için .72, narsisizm için .73 ve psikopati için .76 olarak bulunmuştur.

Rosenberg Benlik Saygısı Ölçeği: Bu ölçek Rosenberg (1965) tarafindan geliştirilmiştir. 63 maddesi bulunan ölçeğin 12 alt ölçeği bulunmaktadır. Benlik saygısı alt ölçeği 4'lü likert tipi 10 maddeden oluşmaktadır. Korkmaz ve Uysal (1996) tarafindan yapılan çalışmada ölçeğin Cronbach Alfa güvenirlik katsayısı .85 olarak hesaplanmıştır. Bu çalışmada Cronbach Alfa güvenirlik katsayıs1 .74 olarak bulunmuştur.

Kişilerarası Tepkisellik Indeksi (IRI): Bu ölçek bireylerin empati ve başkalarının bakış açısını alma özelliklerini ölçmek amacıyla Davis (1983) tarafindan geliştirilmiştir. Toplam madde sayısı 28 olan, 5'li likert tipi ölçeğin, 4 adet alt ölçeği bulunmaktadır. Bu çalışmada bakış açısı alma ve empati değişkenini içeren alt ölçekleri kullanılmıştır. Başkalarının bakış açısını alma ve empati alt ölçeklerinin Cronbach Alfa iç tutarlık katsayısı tarafından yapılan çalışmada .59 ve .60 olarak bulunmuştur (Kumru, Carlo ve Edwards, 2004). Bu çalışmada Cronbach Alfa güvenirlik katsayısı empati için .61, bakış açısı alma için .76 olarak bulunmuştur.

Senaryolar: Bu bölümde araştırmacı tarafından oluşturulan senaryolar verilmiştir. Hedef bireye karşı hissedilen zararına sevinme ve sempati duygusunu ölçmek amacıyla 3 farklı senaryo oluşturulmuştur. Söz konusu senaryolar oluşturulurken James ve arkadaşları (2014) tarafından yapılan çalışmada kullanılan senaryolar araştırmacı tarafından dilimize uyarlanmıştır. Söz konusu senaryolara ilişkin zararına sevinme ve sempati duygusunu ölçen sorular Van Dijk ve arkadaşları (2011) araştırmacı tarafından dilimize uyarlanmıştır. Bu çalışmada zararına sevinme ve sempati ölçümlerinin Cronbach Alfa güvenirlik katsayısı ilk senaryo için .85 ve .77 ; ikinci senaryo için .91 ve .82 ; üçüncü senaryo için .91 ve .77 olarak bulunmuştur.

Senaryo 1: "Son model spor bir araba, aracınızı yakından takip ediyor. Siz aracınızı kullanmaya çalışırken, takip mesafesinin ötesine geçerek sizi trafikte sıkıştırıyor. Ardından sizi hatalı bir şekilde sollayarak geçiyor. O esnada trafik ışıkları kırmızıya dönüyor. Sizi sollayan araç da kırmızı 1şıkta frene basamıyor ve geçiyor. EDS (Elektronik Denetleme Sistemi) kameralarına yakalandığı için, trafik cezası ödemek zorunda kalacak.” 
Senaryo 2: "Arkadaşlarınızla beraberlik seçeneği olmayan bir futbol maçı yapıyorsunuz. Takımlardan biri kaybederken, diğeri de maçı kazanmış olacak. Rakip takımın golcü oyuncusu, kendi takımındaki oyuncuların becerileriyle maç boyunca sürekli övünüyor, muhteşem birtakım olduklarından, çok iyi goller attıklarından bahsediyor. Maçın bitmesine son 15 dakika kala, rakip takımdaki golcü oyuncu, şık ve gösterişli bir hareket yapmak isterken düşüyor ve ayak bileğini incitiyor."

Senaryo 3: "İş yerinde, her şeyi bilen ve sürekli kendi becerileriyle övünen bir çalışma arkadaşın var. Bir gün tesadüfen, çalışma arkadaşının performansının olumsuz biçimde değerlendirildiğini ve bu yüzden de eleştirildiğini öğreniyorsun.”

\section{Yardım davranışı.}

Yardım davranışı, yardım kuruluşuna bağı̧̧ yapma miktarını ölçen bir soruyla ölçülmüştür. Söz konusu ölçüm, Kahane ve arkadaşları (2017) tarafından yapılan çalışmada kullanılan yardım davranışı ölçümünden yararlanılarak oluşturulmuştur.

Yardım Davranışı Sorusu: İş başvurunuza kabul aldınız ve çalışmaya başladınız. Maaşınızı aldığınız ilk bir yılın sonunda, ihtiyaç sahibi insanların yiyecek ve barınma ihtiyacını karşılamak üzere bir yardım kampanyası başlatılıyor. Bu kampanyada, çalışanlarının tümüne maaşlarına ek olarak $300 \mathrm{TL}$ prim yatırılıyor. Bu primin bir kısmını başlatılan yardım kampanyasına yatırma seçeneğiniz, ya da tamamını kendinize saklama seçeneğiniz var. Eğer 300 TL'nin tamamını yatırırsanız, iş yerinizde 300 TL kadar daha bağış yapıyor, eğer $50 \mathrm{TL}$ yatırırsanız iş yeriniz de $50 \mathrm{TL}$ bağış yapıyor. Her bir kişinin yaptığı bağış için, şirket o kadar daha bağış yapıyor. Ne kadar bağış yaptınız başka hiç kimse tarafindan bilinmiyor, bağışlar çevrimiçi sistemde alınıyor ve isminiz gizli tutuluyor. Bu durumda 300 TL'nin ne kadarını bağışlarsınız? Miktarını belirtiniz.

\section{İşlem}

Ölçekler öğrencilere çevrimiçi olarak sunulmuştur. Katılımcılar sırasıyla, demografik bilgi formunu, Karanlık Üçlü Ölçeğini, Kişilerarası Tepkisellik İndeksini, senaryolarla ilgili soruları ve yardım davranışı ile ilgiyi soruyu cevaplamışlardır. Veriler 2018 yılının Ağustos-Ekim ayları arasında toplanmıştır. 


\section{Bulgular}

Yapılan korelasyon analizleri sonucunda yardım davranışının, Makyavelizm puanı ile negatif yönde ve anlamlı düzeyde $(\mathrm{r}(293)=-.21, p<.001)$; psikopati puanı ile negatif yönde ve anlamlı düzeyde $(\mathrm{r}(293)=-.29, p<.001)$; benlik saygısı puanı ile pozitif yönde ve anlamlı düzeyde $(\mathrm{r}(293)=.15, p<.05)$; empati puanı ile pozitif yönde ve anlamlı düzeyde $(\mathrm{r}(293)=.25, \mathrm{p}<.001)$; bakış açısı puanı ile pozitif yönde ve anlamlı düzeyde $(\mathrm{r}(293)=.22, p<.001)$; ikinci zararına sevinme senaryosu puanı ile negatif yönde ve anlamlı düzeyde $(\mathrm{r}(293)=-.12, p<.05)$ ve ikinci sempati senaryosu puanı ile pozitif yönde ve anlamlı düzeyde ilişkili olduğu bulunmuştur $(\mathrm{r}(293)=.18, p<.001)$. Yardım davranışı, birinci ve üçüncü zararına sevinme senaryosu ve narsisizm ile anlamlı düzeyde ilişkili bulunmamıştır $(p>.05)$.

Yapılan korelasyon analizleri sonucunda, birinci zararına sevinme senaryosu, ikinci zararına sevinme senaryosu ile pozitif yönde ve anlamlı düzeyde $(\mathrm{r}(293)=.33, p<.001)$; üçüncü zararına sevinme senaryosu ile pozitif yönde ve anlamlı düzeyde $(\mathrm{r}(293)=.41, p<.001)$ ilişkili bulunmuştur. İkinci zararına sevinme senaryosu üçüncü zararına sevinme senaryosu ile pozitif yönde ve anlamlı düzeyde $(\mathrm{r}(293)=.39, p<.001)$ ilişkili bulunmuştur.

Tablo 1. Değişkenlere İlişkin Betimleyici İstatistikler

\begin{tabular}{|c|c|c|c|c|c|c|c|c|c|}
\hline & $M$ & ss & $\begin{array}{c}\text { En Küçük } \\
\text { Puan }\end{array}$ & $\begin{array}{c}\text { En Büyük } \\
\text { Puan }\end{array}$ & & $M$ & ss & $\begin{array}{c}\text { En Küçük } \\
\text { Puan }\end{array}$ & $\begin{array}{c}\text { En Büyük } \\
\text { Puan }\end{array}$ \\
\hline Makyavelizm & 28.31 & 5.64 & 15 & 45 & $\begin{array}{l}\text { Zararına Sevinme } \\
\text { 1.Senaryo }\end{array}$ & 18.58 & 5.94 & 4 & 28 \\
\hline Narsisizm & 27.43 & 5.73 & 9 & 9 & $\begin{array}{l}\text { Sempati } \\
\text { 1.Senaryo }\end{array}$ & 6.16 & 3.26 & 2 & 14 \\
\hline Psikopati & 19.44 & 6.07 & 41 & 38 & $\begin{array}{l}\text { Zararına Sevinme } \\
\text { 2.Senaryo }\end{array}$ & 10.79 & 5.98 & 4 & 28 \\
\hline Benlik Saygıs1 & 3.03 & 1.20 & 0.50 & 5.50 & $\begin{array}{l}\text { Sempati } \\
\text { 2.Senaryo }\end{array}$ & 10.29 & 3.01 & 2 & 14 \\
\hline Empati & 26.92 & 4.38 & 11 & 35 & $\begin{array}{l}\text { Zararına Sevinme } \\
\text { 3.Senaryo }\end{array}$ & 16.27 & 6.64 & 4 & 28 \\
\hline \multirow[t]{2}{*}{$\begin{array}{l}\text { Bakış Açısı } \\
\text { Alma }\end{array}$} & 26.52 & 5.09 & 8 & 35 & $\begin{array}{l}\text { Sempati } \\
\text { 3.Senaryo }\end{array}$ & 7.27 & 3.25 & 2 & 14 \\
\hline & & & & & Yardım Miktarı & 5.62 & 1.74 & 1 & 7 \\
\hline
\end{tabular}

Birinci zararına sevinme senaryosunun, birinci sempati senaryosu ile negatif yönde ve anlamlı düzeyde $(\mathrm{r}(293)=-.43, p<.001)$; Makyavelizm puanı ile pozitif yönde ve anlamlı düzeyde ilişkili olduğu bulunmuştur $(\mathrm{r}(293)=-.20$, $p<.001)$. 
İkinci zararına sevinme senaryosunun, ikinci sempati senaryosu ile negatif yönde ve anlamlı düzeyde $(\mathrm{r}(293)=-.43, p<.001)$; Makyavelizm puanı ile pozitif yönde ve anlamlı düzeyde $(\mathrm{r}(293)=.29, p<.001)$; narsisizm puanı ile pozitif yönde ve anlamlı düzeyde $(\mathrm{r}(293)=.12, p<.05)$; psikopati puanı ile pozitif yönde ve anlamlı düzeyde $(\mathrm{r}(293)=.32, p<.001)$; benlik saygısı puanı ile negatif yönde ve anlamlı düzeyde $(\mathrm{r}(293)=-.15, p<.05)$; empati puanı ile negatif yönde ve anlamlı düzeyde $(\mathrm{r}(293)=-.14, p<.05)$; bakış açısı puanı ile negatif yönde ve anlamlı düzeyde $(\mathrm{r}(293)=-.14, p<.05)$ ve yardım davranışı ile negatif yönde ve anlamlı düzeyde $(\mathrm{r}(293)=-.12, p<.05)$ ilişkili bulunmuştur.

Üçüncü zararına sevinme senaryosu, ikinci sempati senaryosu ile negatif yönde ve anlamlı düzeyde $(\mathrm{r}(293)=-.35, p<.001)$; Makyavelizm puanı ile pozitif yönde ve anlamlı düzeyde $(\mathrm{r}(293)=.24, p<.001)$; psikopati puanı ile pozitif yönde ve anlamlı düzeyde $(\mathrm{r}(293)=.14, p<.05)$; bakış açısı puanı ile negatif yönde ve anlamlı düzeyde $(\mathrm{r}(293)=-.16, p<.01)$ ilişkili bulunmuştur.

Tablo 2. Yardım Davranışının Yordayıcılarına İlişkin Doğrusal Regresyon Analizi

\begin{tabular}{lccccc}
\hline Değişkenler & B & Standart Hata B & B & t & $\boldsymbol{p}$ \\
\hline Sabit & 4.48 & 1.08 & & 4.13 & .00 \\
Makyavelizm & -.03 & .01 & -.09 & -1.59 & .11 \\
Psikopati & -.04 & .01 & -.16 & -2.52 & .01 \\
Benlik Saygısı & .10 & .08 & .07 & 1.26 & .20 \\
Empati & .04 & .02 & .12 & 1.96 & .04 \\
Bakış Açısı Alma & .02 & .02 & .07 & 1.25 & .21 \\
Zararına Sevinme & .01 & .01 & .03 & .52 & .57 \\
2. Senaryo & & & & & \\
Sempati & .04 & .03 & .08 & 1.33 & .18 \\
2. Senaryo & & & & & \\
\hline P..37,
\end{tabular}

Çalışmanın birinci hipotezi doğrultusunda, yardım davranışının ilişkili olduğu değişkenler bakımından ne düzeyde yordandığını belirlemek amacıyla doğrusal regresyon analizi yapılmıştır. Benlik saygısı, ikinci zararına sevinme ve sempati senaryosu, Makyavelizm, psikopati, empati ve bakış açısı alma puanlarının yardım davranışını birlikte \%14 oranında açıkladığı görülmüştür. Yardım davranışının negatif yönde ve anlamlı yordayıcısı psikopati $(\beta=-.16$, $p<.05)$ ve pozitif yönde ve anlamlı düzeyde yordayıcısı empati puanıdır $(\beta=1.96, p<.05)$. 
Çalışmanın ikinci hipotezi doğrultusunda üç farklı zararına sevinme senaryosunun her birinin hangi değişkenler tarafından anlamlı düzeyde yordandığını anlamak amacıyla doğrusal regresyon analizi yapılmıştır. Birinci zararına sevinme senaryosunun, sempati ve Makyavelizm puanları bakımından \%23 oranında açıkladığı görülmüştür. Zararına sevinme puanının, negatif yönde ve anlamlı yordayıcısı sempati $(\beta=-.43, p<.001)$ ve pozitif yönde ve anlamlı düzeyde yordayıcısı Makyavelizm puanıdır $(\beta=.20, p<.001)$.

Tablo 3. Birinci Zararına Sevinme Senaryosunun Yordayıcılarına İlişkin Doğrusal Regresyon Analizi

\begin{tabular}{lccccc}
\hline Değişkenler & B & Standart Hata B & B & t & $\boldsymbol{p}$ \\
\hline Sabit & 17.35 & 1.66 & & 10.39 & .00 \\
Sempati & -.79 & .09 & -.43 & -8.46 & .00 \\
1. Senaryo & .21 & .05 & .20 & 3.99 & .00 \\
Makyavelizm & .05
\end{tabular}

İkinci zararına sevinme senaryosunun, sempati, Makyavelizm, narsisizm, psikopati, bakış açısı alma, empati, benlik saygısı ve yardım davranışı puanları bakımından \%27 oranında açıkladığı görülmüştür. Zararına sevinme puanının, negatif yönde ve anlamlı yordayıcıları sempati $(\beta=-.38, p<.001)$ ve pozitif yönde ve anlamlı düzeyde yordayıcıları Makyavelizm $(\beta=.16, p<.001)$ ve psikopati puanlarıdır $(\beta=.21, p<.001)$.

Tablo 4. İkinci Zararına Sevinme Senaryosunun Yordayıcılarına İlişkin Doğrusal Regresyon Analizi

\begin{tabular}{lccccc}
\hline Değişkenler & B & Standart Hata B & $\boldsymbol{\beta}$ & $\mathbf{t}$ & $\boldsymbol{p}$ \\
\hline Sabit & 7.33 & 3.50 & & 2.09 & .03 \\
Makyavelizm & .17 & .06 & .16 & 2.92 & .00 \\
Sempati 2. Senaryo & -.74 & .10 & -.38 & -7.05 & .00 \\
Psikopati & .20 & .06 & .21 & 3.29 & .00 \\
Narsisizm & -.02 & .06 & -.02 & -.35 & .72 \\
Benlik Saygıs1 & -.31 & .28 & -.06 & -1.11 & .26 \\
Empati & .09 & .07 & .06 & 1.15 & .24 \\
Bakış Açı1S1 Alma & .02 & .06 & .02 & .36 & .71 \\
Yardım Davranış1 & .09 & .18 & .02 & .52 & .59 \\
\hline $\mathrm{R}=.52 \mathrm{R}^{2}=.27 \mathrm{~F}(8-284)=13.07$ & $p<.001$ & & & &
\end{tabular}

Üçüncü zararına sevinme senaryosunun, sempati, Makyavelizm, psikopati ve bakış açısı alma puanları bakımından \%18 oranında açıkladığı görülmüştür. Zararına sevinme puanının, negatif yönde ve anlamlı yordayıcısı sempati $(\beta=-.33, p<.001)$ ve pozitif yönde ve anlamlı düzeyde yordayıcısı Makyavelizm puanıdır $(\beta=.22, p<.001)$. 
Tablo 5. Üçüncü Zararına Sevinme Senaryosunun Yordayıcılarına İlişkin Doğrusal Regresyon Analizi

\begin{tabular}{lccccc}
\hline Değişkenler & B & Standart Hata B & $\boldsymbol{\beta}$ & $\mathbf{t}$ & $\mathbf{p}$ \\
\hline Sabit & 4.48 & 1.08 & & 4.13 & .00 \\
Makyavelizm & .26 & .06 & .22 & 3.85 & .00 \\
Psikopati & .01 & .06 & .01 & .19 & .84 \\
Bakiş Açı1S1 Alma & -.06 & .07 & -.05 & -.85 & .39 \\
Sempati 3. Senaryo & -.68 & .11 & -.33 & -6.17 & .00 \\
\hline $\mathrm{R}=.43, \mathrm{R}^{2}=.18, \mathrm{~F}(4-289)=16.28, p<.001$ & & & &
\end{tabular}

Cinsiyete göre değişkenler bakımından farklılıklara bakıldığında, erkeklerin Makyavelizm puanının anlamlı düzeyde yüksek olduğu bulunmuştur $(\mathrm{t}=-2.70, p<.01)$. Erkeklerin psikopati puanının anlamlı düzeyde yüksek olduğu bulunmuştur $(\mathrm{t}=-2.89, p<.01)$. Erkeklerin 1. senaryo zararına sevinme puanının anlamlı düzeyde yüksek olduğu bulunmuştur $(\mathrm{t}=-2.89, p<.01)$. Kadınların yardım etme puanının anlamlı düzeyde yüksek olduğu bulunmuştur $(\mathrm{t}=2.31, p<.05)$. Kadınların empati puanının anlamlı düzeyde yüksek olduğu bulunmuştur $(\mathrm{t}=3.34, p<.01)$.

\section{Sonuç, Tartışma ve Öneriler}

$\mathrm{Bu}$ çalışmanın iki amacı vardır. Birinci amaç yardım davranışlarının, karanlık üçlü, benlik saygısı, empati, bakış açısı alma ve zararına sevinme bakımından ne düzeyde açıklandığının belirlenmesidir. Bu amaç doğrultusunda yapılan analizlerde yardım davranışlarının, karanlık üçlü kişilik özelliklerinden kişisel çıkarların diğerlerinin çıkarlarından üstün tutulması ile tanımlanan Makyavelizm ile negatif yönde ilişkili olduğu bulunmuştur. Makyavelizm, kişisel çıkarların maksimize edilmesi, insanları yönlendirme ve yönetme istenci, yönlendirmeye başvurmak gibi özellikler tanımlanmaktadır. Yapılan çalışmalarda, Makyavelizm özelliğinin, yardım davranışlarıyla negatif yönde ilişkili olduğu görülmektedir (Bereczkei, Birkas ve Kerekes, 2010; Berger, Batanova ve Cance, 2015; Lang, 2015). Yardım davranışları ile psikopati özelliğinin de negatif yönde ilişkili olduğu bulunmuştur. Yapılan çalışmalarda, vicdan azabı duymama, saldırganlık gibi özelliklerle karakterize edilen psikopati özelliğinin yardım davranışları ile negatif yönde ilişkili olduğu bulunmuştur (Djeriouat ve Trémolière, 2014; Jonason, Li ve Teicher, 2010). Yardım davranışları beklenildiği gibi, empati ve bakış açısı alma özellikleri ile pozitif yönde ve anlamlı düzeyde ilişkili bulunmuştur. Yapılan çalışmalarda yardım davranışlarının bu özelliklerle ilişkili olduğu görülmektedir (Eisenberg, Zhou ve Koller, 2001; Kumru ve ark., 2012; Sze, Gyurak, Goodkind ve Levenson; 
2012). Yardım davranışları yalnızca ikinci zararına sevinme senaryosu ile negatif yönde, sempati ile pozitif yönde ilişkili bulunmuştur. Benzeri biçimde yapılan çalışmalarda zararına sevinme duygusunun yardım davranışları negatif yönde ilişkili olduğu görülmektedir (Greitemeyer, Osswald ve Brauer, 2010; Schulz ve ark., 2013). Yalnızca ikinci senaryonun yardım davranışı ile ilişkili bulunmasının olası nedenleri, bu senaryoda kişisel kazanım ve rekabet unsurunun ön planda olması ve hedef kişinin uğradığ zararın, diğer senaryolarla kıyaslandığında, daha fazla olmasıdır. Benzeri biçimde, Berndsen ve Feather (2016), hedef kişinin olaydaki sorumluluğu, uğradığı zararın ciddiyeti ve ona karşı hissedilen şefkatin, zararına sevinme duygusunu azaltırken, yardım davranışını arttırdığını bulmuştur. Söz konusu senaryo aynı zamanda, karanlık üçlü kişilik özelliklerinin tümüyle pozitif yönde ilişkili bulunurken, hem empati hem de bakış açısı alma özelliği ile negatif yönde ilişkili bulunan tek senaryodur.

Yapılan regresyon analizi sonucunda, yardım davranışının, benlik sayg1s1, ikinci zararına sevinme ve sempati senaryosu, Makyavelizm, psikopati, empati ve bakış açısı alma puanlarının yardım davranışını birlikte \%14 oranında açıkladığı görülmüştür. Modele anlamlı katkı yapan değişkenlerin empati ve psikopati olduğu görülmüştür. Söz konusu bulgu yapılan çalışmalarla tutarlıdır (Eisenberg, Zhou ve Koller, 2001; Jonason, Li ve Teicher, 2010; Sze ve ark., 2012). Ancak zararına sevinme duygusu yardım davranışına doğrudan etki etmemektedir. Berndsen ve Feather (2016) tarafindan yapılan çalışmada, empati duygusunun, ahlaki duyguları (suçluluk, pişmanlık) harekete geçirerek, zararına sevinme duygusunu azalttığı aynı zamanda bu durumun yardım davranışlarını arttırdığı bulunmuştur. Bu bağlamda, bu çalışmada söz konusu ilişkinin doğrudan tespit edilememesinin nedeninin, empati, bakış açısı alma, karanlık üçlü değişkenlerinin özellik olarak, zararına sevinme duygusunun ise durumsal olarak ölçülmesi olduğu düşünülmektedir.

Çalışmanın ikinci amacı doğrultusunda zararına sevinme senaryolarının, sempati, karanlık üçlü, benlik saygısı, empati, bakış açısı alma ve yardım davranışları bakımından ne düzeyde açıklandığının araştırılması hedeflenmiştir. Her bir senaryo, farklı bir unsura dayandığ i için, analizleri ayrı olarak ele alınmıştır. Ancak her bir senaryoda zararına sevinme duygusunun, söz konusu senaryoya yönelik sempati duygusu ile negatif yönde ve anlamlı düzeyde ilişkili olduğu görülmüştür. Yapılan çalışmalarda benzeri bulgular elde edilmiştir 
(Feather ve Sherman, 2002; Van Dijk ve Ouwerkerk, 2014; Van Dijk, Ouwerkerk, Wesseling ve Van Koningsbruggen, 2011). Regresyon analizi sonucunda birinci senaryodaki zararına sevinme, sempati ve Makyavelizm tarafından anlamlı düzeyde açıklanmıştır. Bu bulgu yapılan çalışmalarla tutarlıdır (Abell ve Brewer, 2018; James, Kavanagh, Jonason, Chonody ve Scrutton, 2014; Porter ve ark., 2014). Birinci senaryo, hak ettiğini bulma ile ilgilidir. $\mathrm{Bu}$ nedenle, karanlık üçlünün diğer özellikleri, empati ve bakış açısı alma özellikleriyle ilişkili olmadığı düşünülmektedir. Benzeri biçimde James ve arkadaşları, (2014) tarafından yapılan çalışmada, benzeri senaryonun bu özelliklerle ilişkili olmadığı görülmüştür.

İkinci senaryodaki zararına sevinme duygusunun, karanlık üçlü, benlik saygısı, empati, bakış açısı alma ve yardım davranışlarıyla ilişkili olduğu görülmüştür. Söz konusu senaryonun daha önce belirtildiği gibi, rekabet ve kişisel kazanım unsurunu barındırmasının karanlık üçlü kişilik özelliklerinin tümüyle ilişkili çıkmasında rol oynadığı düşünülmektedir. Ancak yapılan regresyon analizi sonucunda, yalnızca sempati, Makyavelizm ve psikopati değişkenlerinin anlamlı katkı yaptığı görülmektedir. Yapılan çalışmalarda, psikopati özelliğinin ve saldırgan davranışların zararına sevinme duygusu ile ilişkili olduğu bulunmuştur (James ve ark., 2014; Lane, 2016; Lee, 2019). Benzeri biçimde, Schumpe ve Lafrenière (2016) tarafından yapılan çalışmada, hedef kişinin yaralanma düzeyinin ciddiyeti manipüle edildiğinde, yaralanmanın şiddeti arttıkça hem zararına sevinme duygusunun hem de sadizmin arttığı bulunmuştur. Abell ve Brewer (2018) tarafından yapılan çalışmada, rekabet duygusu ile birlikte Makyavelizm kişilik özelliğinin zararına sevinme duygusunu arttırdığı bulunmuştur.

Üçüncü senaryodaki zararına sevinme duygusunun; sempati, Makyavelizm, psikopati ve perspektif alma özelliği ile ilişkili olduğu bulunmuştur. Yapılan regresyon analizi sonucunda modele anlamlı katkı yapan değişkenlerin yalnızca sempati ve Makyavelizm olduğu görülmüştür. Üçüncü senaryoda, hedef kişinin başına gelen talihsiz durum sonrasında gördüğü zarar, ikinci senaryodaki kişiye göre daha az, birinci senaryodaki kişi ile benzeri düzeydedir. $\mathrm{Bu}$ sebeple birinci ve üçüncü senaryodaki zararına sevinme duygusunun benzer özellikler gösterdiği ve bu yüzden yalnızca sempati ve Makyavelizm özellikleri ile anlamlı düzeyde açıklandığı düşünülmektedir. Buna karşın, üçüncü senaryonun benzeri kullanılarak James ve arkadaşları (2014) tarafından yapılan çalışmada, karanlık üçlünün tüm özelliklerinin zararına sevinme duygusu 
ile ilişkili olduğu görülmüştür. Rekabet düzeyinin söz konusu senaryoda, ikinci senaryoya kıyasla daha az olmasının bu sonucu ortaya çıkarmış olabileceği düşünülmektedir. Aynı zamanda karşılıklı ilişkileri koruma istenci de bunu sağlamış olabilir. Benzeri biçimde Spurgin (2015) zararına sevinme duygusunun, ahlak dışı bir duygu olarak görülmemesine karşın deneyimlenmesinin kişilerarası ilişkilerde gizlenmesi gerekliliğine olan eğilimden bahsetmiştir.

Benlik saygısı birçok çalışmada zararına sevinme ile ilişkili olmasına karşın (Jung, 2017; Van Dijk ve ark., 2009), bu çalışmada, yalnızca ikinci senaryoda anlamlı ilişki bulunmuştur. Diğer bir deyişle, benlik saygısı düşüklüğü, ikinci senaryoda zararına sevinme duygusu ile ilişkilidir.

$\mathrm{Bu}$ çalışmada benlik saygısının doğrudan zararına sevinme duygusuna etki etmeyen bir değişken olmasının nedeninin, benlik saygısının yanında benlik tehdit algısının ölçülmemesi olduğu düşünülmektedir. Yapılan çalışmalarda, benlik saygısı genellikle benlik tehdit algısı ile birlikte ölçülmesine karşın, yalnızca ikisi arasındaki ilişkiyi araştıran çalışmalar mevcuttur (McNamee, 2003; Nagel, 2010; Ouwerkerk ve Van Dijk, 2008). Bu çalışmada benzeri biçimde benlik saygısı bir özellik olarak ölçülmek istenmiş durumsal zararına sevinme duygusu düzeyine nasıl etki ettiği araştırılmak istenmiştir.

Çalışmanın bulguları, yardım davranışlarının, benlik saygısı, durumsal zararına sevinme ve sempati, Makyavelizm, psikopati, empati ve bakış açısı alma özellikleri tarafından anlamlı düzeyde açıklandığını göstermektedir. Ancak modele anlamlı katkı yapan değişkenlerin yalnızca empati ve psikopati olduğu görülmüştür. Bu bağlamda ileride yapılacak çalışmalarda yardım davranışlarının, davranışsal şekilde ölçülmesinin, zararına sevinme ve yardım davranışı arasındaki ilişkiyi anlamada daha fazla katkı sağlayacağı düşünülmektedir. Bunun yanında, empati, perspektif alma değişkenlerinin özellik olarak ölçülmek yerine durumsal ya da fizyolojik olarak ölçülmesinin yardım davranışını anlamada daha fazla katkı sağlayacağı düşünülmektedir. Nitekim, Berndsen ve Feather (2016) tarafindan yapılan çalışmada, empati duygusu manipülasyonu, zararına sevinme duygusunu azaltırken, yardım davranışını arttırmıştır. Zararına sevinme duygusunun farklı senaryolar kullanılarak ölçüldüğü bu çalışmanın bulguları, farklı bağlamlarda zararına sevinme duygusunun farklı değişkenlerle ilişkili olduğunu göstermiştir. Bu bakımdan ileride yapılacak çalışmalarda kullanılan senaryoların, hedef kişinin düştüğü durumdaki sorumluluğu, hedef kişiyle soruyu yanıtlayan kişinin özdeşim düzeyi, 
benlik tehdit algısı gibi unsurları da içermesinin, hem karanlık üçlü kişilik özellikleri, hem de empati ve bakış açısı alma özellikleriyle zararına sevinme duygusu arasındaki ilişkiyi anlamada yararlı olacağı düşünülmektedir. Yardım davranışları ölçümü için önerildiği üzere, zararına sevinme duygusunun da, varsayımsal senaryolarla birlikte davranışsal olarak ölçülmesinin gerekli olduğu düşünülmektedir.

Özetle, çalışmanın bulguları başkalarının üzüntüsünden keyif alma olarak ifade edilen zararına sevinme duygusunun, dolaylı olarak yardım davranışlarıyla, doğrudan kişiliğin karanlık özellikleri olarak tanımlanan psikopati ve Makyavelizm ile ilişkili olduğunu göstermektedir. Bununla birlikte çalışmanın sınırlılığı davranışsal ölçümlere yer verilememesi olarak düşünüldügünde, ileride yapılacak çalışmalarda, başkasının zararına sevinme duygusunun davranışsal ölçümlerle belirlenmesinin alanyazına katkı sağlayacağ 1 düşünülmektedir.

\section{Kaynakça}

Abell, L. ve Brewer, G. (2018). Machiavellianism and schadenfreude in women's friendships. Psychological Reports, 121(5), 909-919.

Doi: 10.1177/0033294117741652

Aristoteles. (2009). Nikomakhos'a etik (2. baskı). (S. Babür, Çev.). İstanbul: Bilgesu Yayınları.

Barnett, M. A. ve Thompson, S. (1985). The role of perspective taking and empathy in children's Machiavellianism, prosocial behavior, and motive for helping. The Journal of Genetic Psychology, 146(3), 295-305.

Doi: 10.1080/00221325.1985.9914459

Batson, D. ve Powell, A. (2003). Alturism and prossocial behavior. T. Millon ve M. J. Lerner, (Ed.), Handbook of Psychology, Personality and Social Psychology (5.cilt) içinde (463-479). New York: Wiley.

Bereczkei, T., Birkas, B. ve Kerekes, Z. (2010). The presence of others, prosocial traits, Machiavellianism. Social Psychology, 41, 238-245.

Doi: 10.1027/1864-9335/a000032

Berger, C., Batanova, M. ve Cance, J. D. (2015). Aggressive and prosocial? Examining latent profiles of behavior, social status, Machiavellianism, and empathy. Journal of Youth and Adolescence, 44(12), 2230-2244.

Doi: 10.1007/s10964-015-0298-9

Berndsen, M. ve Feather, N. T. (2016). Reflecting on schadenfreude: Serious consequences of a misfortune for which one is not responsible diminish previously expressed schadenfreude; the role of immorality appraisals and moral emotions. Motivation and Emotion, 40(6), 895-913.

Doi: 10.1007/s11031-016-9580-8

Brambilla, M. ve Riva, P. (2017). Self image and schadenfreude: Pleasure at others' misfortune enhances satisfaction of basic human needs. European Journal of Social Psychology, 47(4), 399-411. 
Doi: $10.1002 /$ ejsp. 2229

Djeriouat, H. ve Trémolière, B. (2014). The Dark Triad of personality and utilitarian moral judgment: The mediating role of Honesty/Humility and Harm/Care. Personality and Individual Differences, 67, 11-16.

Doi: 10.1016/j.paid.2013.12.026

Eisenberg, N., Fabes, R. A. ve Spinrad, T. L. (2006). Prosocial development. N. Eisenberg, W. Damon ve R. M. Lerner, (Ed.), Handbook of child psychology: social, emotional, and personality development (3. cilt) içinde (646-718). New York: Wiley.

Eisenberg, N., Zhou, Q. ve Koller, S. (2001). Brazilian adolescents' prosocial moral judgment and behavior: Relations to sympathy, perspective taking, gender-role orientation and demographic characteristics. Child Development, 72(2), 518534.

Doi: $10.1111 / 1467-8624.00294$

Feather, N. T. ve Sherman, R. (2002). Envy, resentment, schadenfreude, and sympathy: Reactions to deserved and undeserved achievement and subsequent failure. Personality and Social Psychology Bulletin, 28(7), 953-961.

Doi: $10.1177 / 014616720202800708$

Feather, N. T., Wenzel, M. ve McKee, I. R. (2013). Integrating multiple perspectives on schadenfreude: The role of deservingness and emotions. Motivation and Emotion, 37(3), 574-585.

Doi: $10.1007 / \mathrm{s} 11031-012-9331-4$

Greenier, K. D. (2018). The relationship between personality and schadenfreude in hypothetical versus live situations. Psychological reports, 121(3), 445-458.

Doi: $10.1177 / 0033294117745562$

Greitemeyer, T., Osswald, S. ve Brauer, M. (2010). Playing prosocial video games increases empathy and decreases schadenfreude. Emotion, 10, 796-802. Doi: 10.1037/a0020194

Hoffman, M. L. (2001). Empathy and moral development: Implications for caring and justice. Cambridge University Press.

Jacobs, J. E., Vernon, M. K. ve Eccles, J. S. (2004). Relations between social selfperceptions, time use, and prosocial or problem behaviors during adolescence. Journal of Adolescent Research, 19(1), 45-62.

Doi: 10.1177/0743558403258225

James, S., Kavanagh, P. S., Jonason, P. K., Chonody, J. M. ve Scrutton, H. E. (2014). The Dark Triad, schadenfreude, and sensational interests: dark personalities, dark emotions, and dark behaviors. Personality and Individual Differences, 68, 211-216.

Doi: $10.1016 /$ j.paid.2014.04.020

Jonason, P. K., Li, N. P. ve Teicher, E. A. (2010). Who is James Bond? The Dark Triad as an agentic social style. Individual Differences Research, 8(2), 111120.

Jones, D. N. ve Paulhus, D. L. (2014). Introducing the short dark triad (SD3) a brief measure of dark personality traits. Assessment, 21(1), 28-41.

Doi: $10.1177 / 1073191113514105$

Jung, K. (2017). Happiness as an additional antecedent of schadenfreude. The Journal of Positive Psychology, 12(2), 186-196. 
Doi:10.1080/17439760.2016.1173224

Kahane, G., Everett, J. A. C., Earp, B. D., Caviola, L., Faber, N. S., Crockett, M. J. ve Savulescu, J. (2018). Beyond sacrificial harm: A two-dimensional model of utilitarian psychology. Psychological Review, 125(2), 131-164.

Doi: 10.1037/rev0000093

Kerig, P. K. ve Stellwagen, K. K. (2010). Roles of callous-unemotional traits, narcissism, and Machiavellianism in childhood aggression. Journal of Psychopathology and Behavioral Assessment, 32(3), 343-352.

Doi: 10.1007/s10862-009-9168-7

Korkmaz, M. ve Uysal, Ş. (1996). Yetişkin örneklem için bir benlik saygısı ölçeğinin güvenirlik ve geçerlik çalışması. Yayınlanmamış yüksek lisans tezi, Ege Üniversitesi Sosyal Bilimler Enstitüsü.

Kumru, A., Carlo, G. ve Edwards, C. (2004). Olumlu sosyal davranışların ilişkisel, kültürel, bilişsel ve duyuşsal bazı değişkenlerle ilişkisi. Türk Psikoloji Dergisi, 19(54), 109-125.

Doi: $10.2224 /$ sbp.2012.40.2.205

Kumru, A., Carlo, G., Mestre, M. V. ve Samper, P. (2012). Prosocial moral reasoning and prosocial behavior among Turkish and Spanish adolescents. Social Behavior and Personality: an international journal, 40(2), 205-214.

Laible, D. J., Carlo, G. ve Roesch, S. C. (2004). Pathways to self-esteem in late adolescence: The role of parent and peer attachment, empathy, and social behaviours. Journal of Adolescence, 27(6), 703-716.

Doi: 10.1016/j.adolescence.2004.05.005

Lane, R. (2016). Schadenfreude, the Dark Triad, and the effect of music on emotion. Yayınlanmamış lisans bitirme tezi, Georgia Southern University Faculty of Fine Arts.

Lang, A. (2015). Relationship between Machiavellianism and emotional and behavioral difficulties in adolescence. Orvosi Hetilap, 156(26), 1054-1058.

Doi: $10.1556 / 650.2015 .30175$

Lee, S. A. (2019). The Dark Tetrad and callous reactions to mourner grief: Patterns of annoyance, boredom, entitlement, schadenfreude, and humor. Personality and Individual Differences, 137, 97-100.

Doi: 10.1016/j.paid.2018.08.019

Luengo-Kanacri, B. P., Pastorelli, C., Eisenberg, N., Zuffianò, A. ve Caprara, G. V. (2013). The development of prosociality from adolescence to early adulthood: The role of effortful control. Journal of Personality, 81(3), 302-312.

Doi: 10.1111/jopy.12001

McNamee, M. (2003). Schadenfreude in sport: Envy, justice, and self-esteem. Journal of the Philosophy of Sport, 30(1), 1-16.

Doi: 10.1080/00948705.2003.9714556

Nagel, E. (2010). The significance of gender, context and contingent self-esteem on feelings of schadenfreude. Yayınlanmamıs doktora tezi, Vanderbilt University, Psychology Department.

Ouwerkerk, J. W. ve Van Dijk, W. W. (2008, Haziran). "Don't mention the war": Social identification and salience of rivalry as determinants of intergroup schadenfreude. $15^{\text {th }}$ General Meeting of the European Association for Experimental Social Psychology, Opatija. 
Özsoy, E. ve Ardıç, K. (2017). Karanlık üçlü’nün (narsisizm, Makyavelizm ve psikopati) iş tatminine etkisinin incelenmesi. Yönetim ve Ekonomi, 24(2), 391-406. Doi: 10.18657/yonveek.297733

Özsoy, E., Rauthmann, J. F., Jonason, P. K. ve Ardıç, K. (2017). Reliability and validity of the Turkish versions of Dark Triad Dirty Dozen (DTDD-T), Short Dark Triad (SD3-T), and Single Item Narcissism Scale (SINS-T). Personality and Individual Differences, 117, 11-14.

Doi: 10.1016/j.paid.2017.05.019

Paulhus, D. L. ve Williams, K. M. (2002). The dark triad of personality: narcissism, Machiavellianism, and psychopathy. Journal of Research in Personality, 36(6), 556-563.

Doi: 10.1016/S0092-6566(02)00505-6

Porter, S., Bhanwer, A., Woodworth, M. ve Black, P. J. (2014). Soldiers of misfortune: An examination of the Dark Triad and the experience of schadenfreude. Personality and Individual Differences, 67, 64-68.

Doi: 10.1016/j.paid.2013.11.014

Rosenberg, M. (1965). Rosenberg self-esteem scale (RSE). Acceptance and commit ment therapy. Measures package, 61(52), 18.

Schopenhauer, A. (2014). İnsan doğası üzerine. (E. Yıldırım, Çev.). İstanbul: Oda Yayınları. (Orijinal çalışma basım tarihi 1841.)

Schulz, K., Rudolph, A., Tscharaktschiew, N. ve Rudolph, U. (2013). Daniel has fallen into a muddy puddle-Schadenfreude or sympathy? British Journal of Developmental Psychology, 31(4), 363-378.

Doi: 10.1111/bjdp.12013

Schumpe, B. M. ve Lafrenière, M. A. K. (2016). Malicious joy: Sadism moderates the relationship between schadenfreude and the severity of others' misfortune. Personality and Individual Differences, 94, 32-37.

Doi: 10.1016/j.paid.2016.01.005

Shamay-Tsoory, S. G., Tibi-Elhanany, Y. ve Aharon-Peretz, J. (2007). The greeneyed monster and malicious joy: the neuroanatomical bases of envy and gloating (schadenfreude). Brain, 130(6), 1663-1678.

Doi: 10.1093/brain/awm093

Smith, R. H., Powell, C. A., Combs, D. J. ve Schurtz, D. R. (2009). Exploring the when and why of schadenfreude. Social and Personality Psychology Compass, 3(4), 530-546.

Doi: $10.1111 / \mathrm{j} .1751-9004.2009 .00181 . x$

Spurgin, E. (2015). An emotional-freedom defense of schadenfreude. Ethical Theory and Moral Practice, 18(4), 767-784.

Doi: $10.1007 / \mathrm{s} 10677-014-9550-8$

Sze, J. A., Gyurak, A., Goodkind, M. S. ve Levenson, R. W. (2012). Greater emotional empathy and prosocial behavior in late life. Emotion, 12(5), 1129-1140.

Doi: $10.1037 / \mathrm{a} 0025011$

Tatlıcıoğlu, I. (2015). Dolaylı utanmanın mizah ve başkasının zararına sevinme ile ilişkisi. Yayınlanmamış yüksek lisans tezi, İstanbul Üniversitesi Sosyal Bilimler Enstitüsü.

Torun, G. (2013). Sosyal kimliğin kıskançlık ve başkasının üzüntüsüne sevinme üze- 
rindeki etkileri. Yayınlanmamış yükssek lisans tezi, Hacettepe Üniversitesi Sosyal Bilimler Enstitüsü.

Van Dijk, W. W. ve Ouwerkerk, J. W. (2014). Striving for positive self-evaluation as a motive for schadenfreude. Schadenfreude: Understanding pleasure at the misfortune of others, 131-148.

Van Dijk, W. W., Ouwerkerk, J. W., Wesseling, Y. M. ve Van Koningsbruggen, G. M. (2011). Towards understanding pleasure at the misfortunes of others: The impact of self-evaluation threat on schadenfreude. Cognition and Emotion, 25(2), 360-368.

Doi: 10.1080/02699931.2010.487365

Van Dijk, W. W., Van Koningsbruggen, G. M., Ouwerkerk, J. W. ve Wesseling, Y. M. (2011). Self-esteem, self-affirmation and schadenfreude. Emotion, 11(6), 1445-1449.

Doi: $10.1037 / \mathrm{a} 0026331$

Van Lange, P. A. M. (2008). Does empathy triggers only altruistic motivation: How about selflessness and justice? Emotion, 8, 766-774.

Doi: $10.1037 / \mathrm{a} 0013967$

Wills, T. A. (1981). Downward comparison principles in social psychology. Psychological Bulletin, 90, 245-271.

Doi: 10.1037/0033-2909.90.2.245

Yeniay, Y. (2012). Sosyal kimlik ile algllayan ve algılananın cinsiyetinin başkalarının üzüntüsüne sevinme eğilimi üzerindeki etkileri. Yayınlanmamış yüksek lisans tezi, Hacettepe Üniversitesi Sosyal Bilimler Enstitüsü.

Zuffianò, A., Eisenberg, N., Alessandri, G., Luengo Kanacri, B. P., Pastorelli, C., Milioni, M. ve Caprara, G. V. (2014). The relation of pro-sociality to self-esteem: The mediational role of quality of friendships. Personality and Individual Differences, 63, 24-29.

Doi: $10.1111 /$ jopy.12137 